\title{
A comparison of letrozole and anastrozole followed by letrozole in breast cancer patients
}

This article was published in the following Dove Press journal:

Breast Cancer: Targets and Therapy

20 January 2015

Number of times this article has been viewed

\section{Potchavit Aphinives Damnern Vachirodom Chaiyut Thanapaisal Dhanes Rangsrikajee Ongart Somintara}

Department of Surgery, Faculty of Medicine, Khon Kaen University, Khon Kaen, Thailand

Correspondence: Potchavit Aphinives Department of Surgery, Faculty of Medicine, Khon Kaen University, 123 group I6, Mittraparp Rd, Muang, Khon Kaen province, 40002 , Thailand

Tel +6643363252

Fax +66 43348393

Email potchavit@gmail.com
Background: We previously studied the noninferiority of anastrozole (ANZ) versus ANZ followed by letrozole (A-LTZ) due to reimbursement policy. We found that patients with A-LTZ had better overall survival (OS) than did patients with ANZ alone. This study aimed to prove that patients with A-LTZ also had better OS than patients with letrozole (LTZ) alone.

Methods: All medical records of the breast cancer patients taking LTZ with or without ANZ between 2004 and 2013 were reviewed. All patients were divided into two groups: the LTZ group included patients treated with LTZ alone, and the A-LTZ group included patients treated with ANZ who were automatically changed to LTZ due to change of the reimbursement policy.

Results: From 359 cases, there were 179 cases in the LTZ group and 180 cases in the A-LTZ group. The mean age of patients in the LTZ group was 53.7 years and in the A-LTZ group was 54.2 years. The distribution of clinical stages among the LTZ group versus the A-LTZ group was 21 versus 4 (stage 1), 86 versus 116 (stage 2), 55 versus 46 (stage 3), and 17 versus 14 (stage 4), respectively. Among the LTZ patients, $63.7 \%$ took aromatase inhibitor monotherapy and $36.3 \%$ had a switching strategy, while in the A-LTZ group, 53.9\% took AI monotherapy and $46.1 \%$ had a switching strategy. OS of the A-LTZ group was longer than that of the LTZ group.

Conclusion: The patients in A-LTZ, taking ANZ followed by LTZ had better OS than those in LTZ, taking LTZ alone.

Keywords: estrogen receptor-positive, hormonal responsive, tamoxifen

\section{Introduction}

One of the standard treatments for estrogen receptor-positive breast cancer patients is endocrine therapy. It can be used as an adjuvant for the early stage ${ }^{1}$ or a palliative for the advanced disease. ${ }^{2}$ In Thailand, the available oral antiestrogen drugs include tamoxifen, anastrozole (ANZ), letrozole (LTZ), and exemestane. For premenopausal patients, tamoxifen seems to be the drug of choice, while aromatase inhibitors (AIs) have been used for postmenopausal patients. ${ }^{2-8}$ AIs are divided into two groups: nonsteroidal, which includes ANZ and LTZ, and steroidal, which includes exemestane. A switching strategy using an $\mathrm{AI}$ and tamoxifen is as effective as the AI monotherapy. ${ }^{9,10}$

In Thailand, some breast cancer patients receiving ANZ were automatically switched to LTZ due to the change of the reimbursement policy since 2008 . We studied the outcome of this switching treatment to prove the noninferiority, but found that patients with ANZ followed by LTZ (A-LTZ) had better overall survival (OS) than patients with ANZ alone. ${ }^{11}$ Some studies have shown no difference in OS among AIs, either nonsteroidal or steroidal, ${ }^{12-17}$ some cases changed from ANZ to LTZ due to early adverse effect of ANZ, but no clear superiority of LTZ was demonstrated..$^{7-10,17-21}$ One study showed 
LTZ seemed to be superior to ANZ, but no clear benefit was demonstrated. ${ }^{21}$ From our previous study, ${ }^{11}$ we could not conclude whether A-LTZ was superior or similar to LTZ. So we designed the study comparing patients receiving LTZ and patients receiving A-LTZ during the same period.

\section{Materials and methods}

All medical records of the breast cancer patients taking LTZ between 2004 and 2013 were reviewed. AI therapy included two types of strategy: AI monotherapy for 5 years; or 2-3 years of tamoxifen followed by 2-3 years of AI, up to total of 5 years. All collected patients were divided into two groups: the LTZ group included patients taking LTZ with or without tamoxifen; and the A-LTZ group included patients taking ANZ who were automatically changed to LTZ, either in an AI monotherapy strategy or AI-tamoxifen switching strategy, due to the change of the reimbursement policy. Demographic data, type of reimbursement, endocrine therapy, and OS were reviewed and analyzed.

Demographic data was analyzed using Excel ${ }^{\circledR} 2007$ (Microsoft Corp, Redmond, WA, USA). Survival data was analyzed using Stata version 10.1 (StataCorp LP, College Station, TX, USA). OS was analyzed using a Cox regression model and presented as Kaplan-Meier estimates with hazard ratios (HR) and 95\% confidence interval (CI). The LTZ and A-LTZ groups were compared using logrank test. A $P$-value $<0.05$ was considered statistically significant.

This study was reviewed and approved by the Khon Kaen University Ethics Committee for Human Research and was based on the Declaration of Helsinki and the International Conference on Harmonisation (ICH) Good Clinical Practice Guidelines.

\section{Results}

The medical records of 359 patients with invasive breast cancer treated with LTZ with or without ANZ were reviewed. There were 25 stage 1 patients (mean age 53.6 \pm 11.7 years), 202 stage 2 patients (mean age 53.8 \pm 9.9 years), 101 stage 3 patients (mean age $54.5 \pm 9.8$ years), and 31 stage 4 patients (mean age $53.6 \pm 10.0$ years). In 180 cases (50.1\%) out of 359 cases, ANZ was replaced with LTZ. The mean age of the LTZ group was 53.7 years and of the A-LTZ group was 54.2 years. The distribution of clinical stages among the LTZ group versus the A-LTZ group was 21 versus 4 (stage 1), 86 versus 116 (stage 2), 55 versus 46 (stage 3), and 17 versus 14 (stage 4), respectively. Among the LTZ patients, 63.7\% took AI monotherapy and $36.3 \%$ had a switching strategy, while among the A-LTZ patients, 53.9\% took AI monotherapy and $46.1 \%$ had a switching strategy (Table 1). Within the
A-LTZ group, the average duration of ANZ was 18.7 months. Stage 4 patients took the shortest duration of ANZ, of only 8.7 months, while stage 1 patients took the longest duration, of 24.2 months (Table 1).

The OS of breast cancer patients in the LTZ and A-LTZ groups was analyzed by Cox regression model and presented as Kaplan-Meier survival curve with a HR of 0.6824 (Figure 1), and the OS of the A-LTZ group was found to be significantly better than that of the LTZ group $(P=0.0386)$. When the OS was stratified by each stage (Table 2 ), only stage 4 patients in the A-LTZ group had a significantly better OS than stage-matched patients in the LTZ group $(P=0.0114)$; the Kaplan-Meier survival curve was shown, with a HR of 0.3083 , in Figure 2.

\section{Discussion}

In Thailand, there are three major medical reimbursement systems: the Civil Servant Medical Benefit Scheme (CSMBS) for government officers, Social Security for employees, and

Table I Comparison of demographic data between the LTZ and the A-LTZ groups of patients

\begin{tabular}{|c|c|c|}
\hline Category & $\begin{array}{l}\text { LTZ } \\
(n=179)\end{array}$ & $\begin{array}{l}\text { A-LTZ } \\
(n=180)\end{array}$ \\
\hline Mean age (years) & $53.7 \pm 9.7$ & $54.2 \pm 10.2$ \\
\hline \multicolumn{3}{|l|}{ Clinical staging } \\
\hline - Stage I & $21(11.73 \%)$ & $4(2.22 \%)$ \\
\hline - Stage 2 & $86(48.04 \%)$ & $116(64.44 \%)$ \\
\hline - Stage 3 & $55(30.73 \%)$ & $46(25.55 \%)$ \\
\hline - Stage 4 & $17(9.50 \%)$ & $14(7.77 \%)$ \\
\hline \multicolumn{3}{|c|}{ Type of reimbursement } \\
\hline - CSMBS & 89 (49.72\%) & $83(46.11 \%)$ \\
\hline - Non-CSMBS & $90(50.28 \%)$ & 97 (53.89\%) \\
\hline \multicolumn{3}{|c|}{ Endocrine treatment strategy } \\
\hline - Al only & II4 (63.69\%) & 97 (53.89\%) \\
\hline$\circ$ Stage I & $18(\mid 5.79 \%)$ & $2(2.06 \%)$ \\
\hline - Stage 2 & $60(52.63 \%)$ & $59(60.82 \%)$ \\
\hline$\circ$ Stage 3 & $32(28.07 \%)$ & $29(29.90 \%)$ \\
\hline$\circ$ Stage 4 & $4(3.5 \mid \%)$ & 7 (7.22\%) \\
\hline - $\mathrm{Al}+$ tamoxifen & $65(36.31 \%)$ & $83(46.11 \%)$ \\
\hline ○ Stage I & $3(4.62 \%)$ & $2(2.4 \mid \%)$ \\
\hline - Stage 2 & $26(40.00 \%)$ & $57(68.67 \%)$ \\
\hline ○ Stage 3 & $23(35.38 \%)$ & $17(20.48 \%)$ \\
\hline$\circ$ Stage 4 & $13(20.00 \%)$ & 7 (8.43\%) \\
\hline \multirow{2}{*}{\multicolumn{3}{|c|}{$\begin{array}{l}\text { Anastrozole duration } \\
\text { (mean } \pm \mathrm{SD} \text {, months) }\end{array}$}} \\
\hline & & \\
\hline All & & $18.7 \pm 14.6$ \\
\hline - Stage I & & $24.2 \pm 18.6$ \\
\hline - Stage 2 & & $19.9 \pm 15.7$ \\
\hline - Stage 3 & & $18.4 \pm \mid 4.4$ \\
\hline - Stage 4 & & $8.7 \pm 4.8$ \\
\hline
\end{tabular}

Abbreviations: Al, aromatase inhibitor; A-LTZ, anastrozole followed by letrozole; CSMBS, Civil Servant Medical Benefit Scheme (for government officers); LTZ, letrozole; SD, standard deviation. 


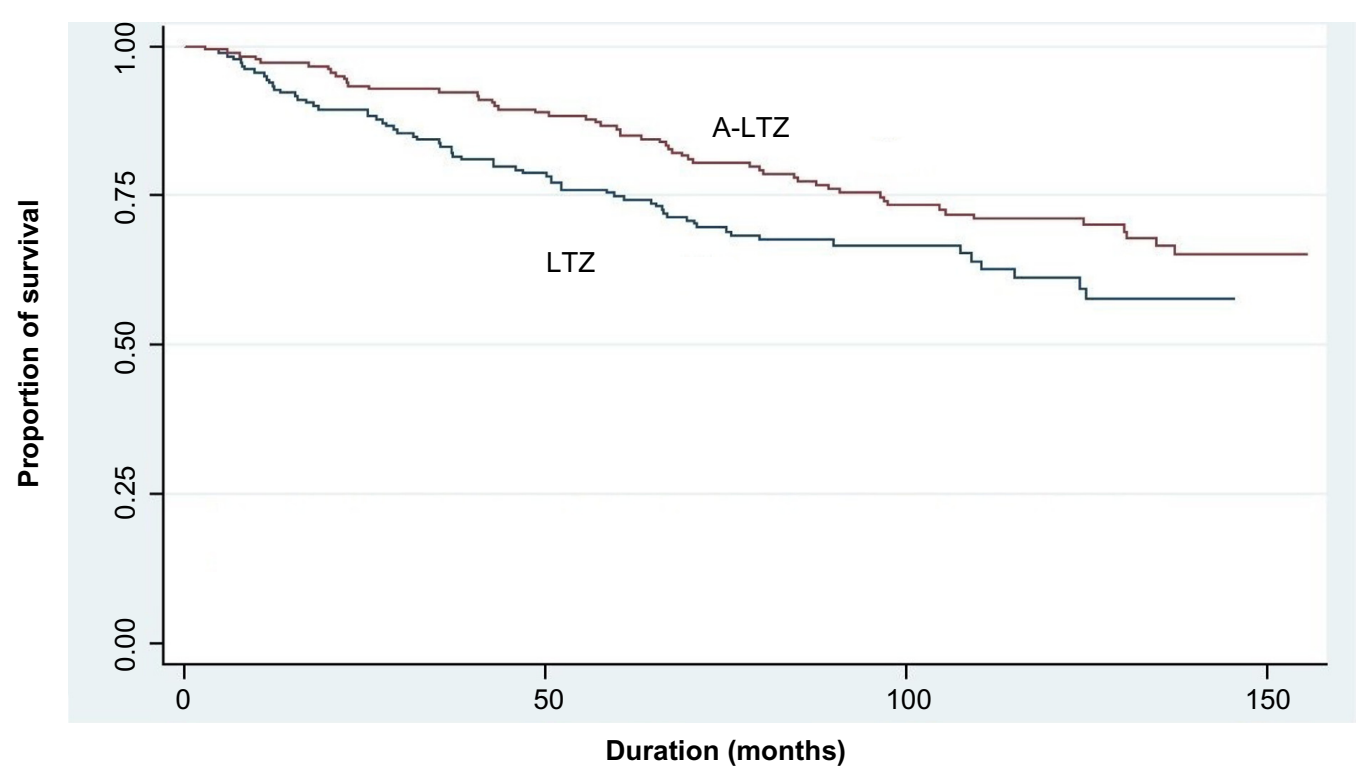

Figure I Kaplan-Meier survival curve of the LTZ and the A-LTZ groups of patients (all stages).

Abbreviations: A-LTZ, anastrozole followed by letrozole; LTZ, letrozole.

Universal Coverage for all the remaining Thai people. On average, government officers have higher socioeconomic status than most Thai people. The proportions of CSMBS and non-CSMBS patients in the LTZ group (50:50) were higher than in the A-LTZ group (46:54). We classified the reimbursement systems into CSMBS and non-CSMBS because higher socioeconomic status might have a longer survival than lower socioeconomic status. In comparison, in our previous study, ${ }^{11}$ the proportions of CSMBS and non-CSMBS patients, respectively, in the ANZ group were nearly the same as those in the A-LTZ group (45:55 [ANZ] versus 46:54 [A-LTZ]). Although the OS of both the LTZ and ANZ groups differed significantly from the A-LTZ group, the HR of LTZ (0.6824) was higher than that of the ANZ (0.5515) group.

Some studies ${ }^{9,10,13,22}$ have reported the superiority of AI to tamoxifen but no significant difference in disease-free survival between the switching strategy compared with AI monotherapy strategy. However, AI produced more

Table 2 Survival analysis between the LTZ and the A-LTZ groups of patients

\begin{tabular}{lll}
\hline Stage & $\begin{array}{l}\text { Hazard ratio } \\
\text { (95\% confidence interval) }\end{array}$ & P-value \\
\hline All & $0.6824(0.4741-0.9823)$ & $0.0386^{*}$ \\
I & - & 0.3783 \\
2 & $0.5885(0.3226-1.0738)$ & 0.0805 \\
3 & $1.0618(0.6063-1.8598)$ & 0.8337 \\
4 & $0.3083(0.1180-0.8053)$ & $0.0114^{*}$ \\
\hline
\end{tabular}

Note: *Statistical significance.

Abbreviations: A-LTZ, anastrozole followed by letrozole; LTZ, letrozole. adverse events than tamoxifen, so we had to consider the survival benefit between the two strategies. ${ }^{19,22-24}$ The difference of HR between LTZ and ANZ groups might be affected by the proportions of AI monotherapy and switching strategy (64:36 versus 54:46). ${ }^{11}$

This study confirmed that treatment with A-LTZ should lengthen the survival of hormone-sensitive breast cancer patients better than LTZ or ANZ. The efficacy of LTZ was shown to be the same as ANZ in several studies, ${ }^{12-14}$ although some studies have shown LTZ might be superior to ANZ in terms of quality of life, due to lower incidence of adverse events. ${ }^{25,26}$ But there were no data about sequential therapy of ANZ and LTZ. Both drugs were classified in the same group - nonsteroidal AI. So it seemed to be irrational using both drugs sequentially, even with their different chemical structure. ${ }^{14}$ We observed the shortest duration of ANZ usage with narrowest standard deviation in stage 4 patients of the A-LTZ group, which might relate to statistical significance in the OS difference between the two groups. However, this retrospective study with small number of patients can reach limited conclusions. Further prospective study with larger number of patients should be performed to confirm the better outcome of sequential therapy of ANZ and LTZ.

\section{Conclusion}

The patients in the A-LTZ group, taking A-LTZ, seemed to have better OS than those in the LTZ group, taking LTZ alone. 


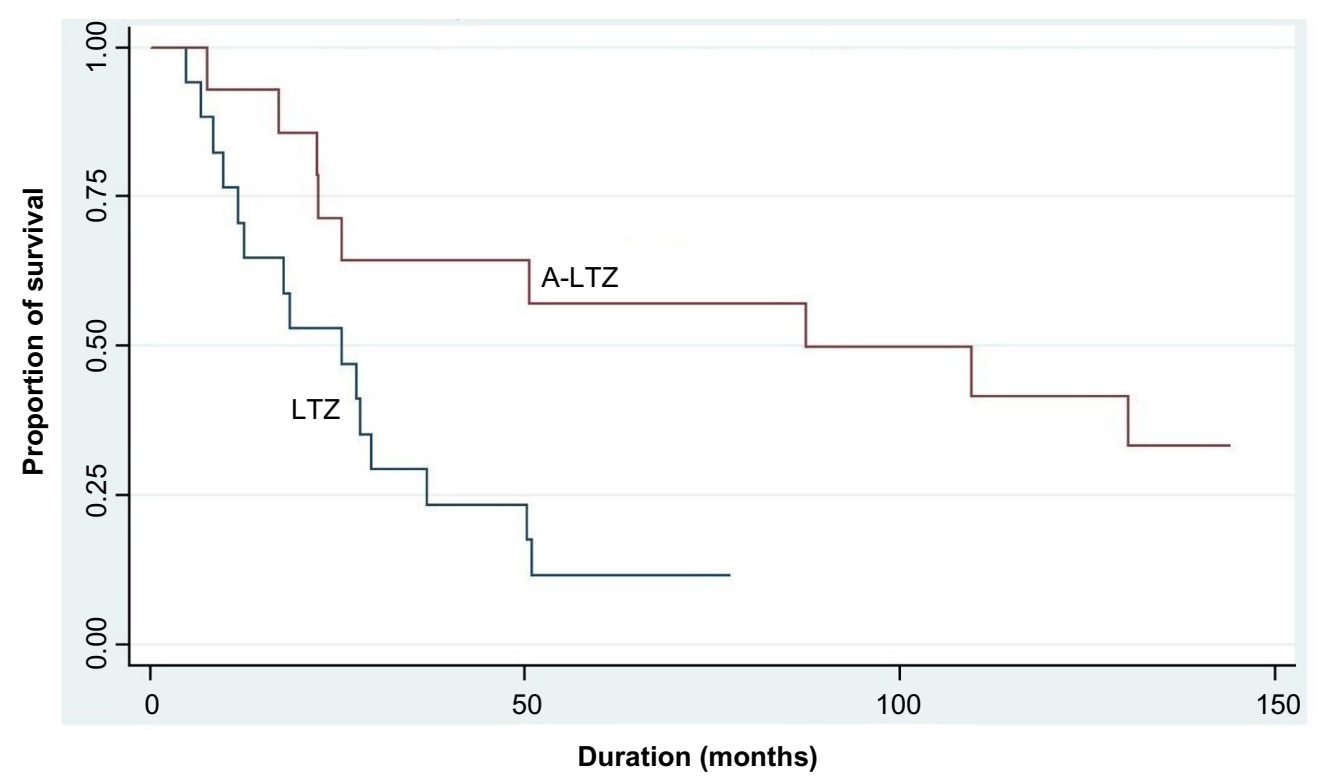

Figure 2 Kaplan-Meier survival curve of stage 4 LTZ and A-LTZ patients.

Abbreviations: A-LTZ, anastrozole followed by letrozole; LTZ, letrozole.

\section{Disclosure}

The authors report no conflicts of interest in this work.

\section{References}

1. Connor C, Attai D. Adjuvant endocrine therapy for the surgeon: options, side effects, and their management. Ann Surg Oncol. 2013;20(10): 3188-3193.

2. Smith IE, Dowsett M. Aromatase inhibitors in breast cancer. New Engl J Med. 2003;348(24):2431-2442.

3. Forbes JF, Cuzick J, Buzdar A, Howell A, Tobias JS, Baum M; Arimidex, Tamoxifen, Alone or in Combination (ATAC) Trialists' Group. Effect of anastrozole and tamoxifen as adjuvant treatment for early-stage breast cancer: 100-month analysis of the ATAC trial. Lancet Oncol. 2008;9(1):45-53.

4. Cuzick J, Sestak I, Baum M, et al; ATAC/LATTE Investigators. Effect of anastrozole and tamoxifen as adjuvant treatment for early-stage breast cancer: 10-year analysis of the ATAC trial. Lancet Oncol. 2010;11(12): $1135-1141$

5. Davies C, Pan H, Godwin J, et al; Adjuvant Tamoxifen: Longer Against Shorter (ATLAS) Collaborative Group. Long-term effects of continuing adjuvant tamoxifen to 10 years versus stopping at 5 years after diagnosis of oestrogen receptor-positive breast cancer: ATLAS, a randomised trial. Lancet. 2013;381(9869):805-816.

6. Goss PE, Ingle JN, Martino S, et al. A randomized trial of letrozole in postmenopausal women after five years of tamoxifen therapy for earlystage breast cancer. N Engl J Med. 2003;349(19):1793-1802.

7. Jakesz R, Jonat W, Gnant M, et al; ABCSG and the GABG. Switching of postmenopausal women with endocrine-responsive early breast cancer to anastrozole after 2 years' adjuvant tamoxifen: combined results of $\mathrm{ABC}$ SG trial 8 and ARNO 95 trial. Lancet. 2005;366(9484):455-462.

8. Burstein HJ, Prestrud AA, Seidenfeld J, et al; American Society of Clinical Oncology. American Society of Clinical Oncology clinical practice guideline: update on adjuvant endocrine therapy for women with hormone receptor-positive breast cancer. J Clin Oncol. 2010;28(23):3784-3796.

9. van de Velde CJ, Rea D, Seynaeve C, et al. Adjuvant tamoxifen and exemestane in early breast cancer (TEAM): a randomised phase 3 trial. Lancet. 2011;377(9762):321-331.
10. Mouridsen H, Giobbie-Hurder A, Goldhirsch A, et al; BIG 1-98 Collaborative Group. Letrozole therapy alone or in sequence with tamoxifen in women with breast cancer. N Engl J Med. 2009;361(8):766-776.

11. Aphinives P, Vachirodom D, Thanapaisal C, Rangsrikajee D, Somintara O. Effects of switching from anastrozole to letrozole, due to reimbursement policy, on the outcome of breast cancer therapy. Breast Cancer (Dove Med Press). 2014;6:145-150.

12. Dixon JM, Renshaw L, Langridge $C$, et al. Anastrozole and letrozole: an investigation and comparison of quality of life and tolerability. Breast Cancer Res Treat. 2011;125(3):741-749.

13. Riemsma R, Forbes CA, Kessels A, et al. Systematic review of aromatase inhibitors in the first-line treatment for hormone sensitive advanced or metastatic breast cancer. Breast Cancer Res Treat. 2010;123(1):9-24.

14. Geisler J. Differences between the non-steroidal aromatase inhibitors anastrozole and letrozole - of clinical importance? Br J Cancer. 2011;104(7):1059-1066.

15. Goss PE, Ingle JN, Pritchard KI, et al. Exemestane versus anastrozole in postmenopausal women with early breast cancer: NCIC CTG MA.27 - a randomized controlled phase III trial. J Clin Oncol. 2013;31(11):1398-1404.

16. Ellis MJ, Suman VJ, Hoog J, et al. Randomized phase II neoadjuvant comparison between letrozole, anastrozole, and exemestane for postmenopausal women with estrogen receptor-rich stage 2 to 3 breast cancer: clinical and biomarker outcomes and predictive value of the baseline PAM50-based intrinsic subtype - ACOSOG Z1031. J Clin Oncol. 2011;29(17):2342-2349.

17. Fabian CJ. The what, why and how of aromatase inhibitors: hormonal agents for treatment and prevention of breast cancer. Int J Clin Pract. 2007;61(12):2051-2063.

18. Beresford M, Tumur I, Chakrabarti J, Barden J, Rao N, Makris A. A qualitative systematic review of the evidence base for non-cross-resistance between steroidal and non-steroidal aromatase inhibitors in metastatic breast cancer. Clin Oncol (R Coll Radiol). 2011;23(3):209-215.

19. Fontein DB, Seynaeve C, Hadji P, et al. Specific adverse events predict survival benefit in patients treated with tamoxifen or aromatase inhibitors: an international tamoxifen exemestane adjuvant multinational trial analysis. J Clin Oncol. 2013;31(18):2257-2264.

20. Friese CR, Pini TM, Li Y, et al. Adjuvant endocrine therapy initiation and persistence in a diverse sample of patients with breast cancer. Breast Cancer Res Treat. 2013;138(3):931-939. 
21. Berry J. Are all aromatase inhibitors the same? A review of controlled clinical trials in breast cancer. Clin Ther. 2005;27(11):1671-1684.

22. Thürlimann B, Keshaviah A, Coates AS, et al; Breast International Group (BIG) 1-98 Collaborative Group. A comparison of letrozole and tamoxifen in postmenopausal women with early breast cancer. $N$ Engl J Med. 2005;353(26):2747-2757.

23. Amir E, Seruga B, Niraula S, Carlsson L, Ocaña A. Toxicity of adjuvant endocrine therapy in postmenopausal breast cancer patients: a systematic review and meta-analysis. J Natl Cancer Inst. 2011; 103(17):1299-1309.
24. Fallowfield L, Cella D, Cuzick J, Francis S, Locker G, Howell A. Quality of life of postmenopausal women in the Arimidex, Tamoxifen, Alone or in Combination (ATAC) Adjuvant Breast Cancer Trial. J Clin Oncol. 2004;22(21):4261-4271.

25. Thomas R. Examining quality of life issues in relation to endocrine therapy for breast cancer. Am J Clin Oncol. 2003;26(4):S40-S44.

26. Thomas R, Godward S, Makris A, Bloomfield D, Moody AM, Williams M. Giving patients a choice improves quality of life: a multi-centre, investigator-blind, randomised, crossover study comparing letrozole with anastrozole. Clin Oncol (R Coll Radiol). 2004;16(7): 485-491.

\section{Publish your work in this journal}

Breast Cancer: Targets and Therapy is an international, peerreviewed open access journal focusing on breast cancer research, identification of therapeutic targets and the optimal use of preventative and integrated treatment interventions to achieve improved outcomes, enhanced survival and quality of life for the cancer patient.

\section{Dovepress}

View the full aims and scopes of this journal here. The manuscript management system is completely online and includes a very quick and fair peer-review system, which is all easy to use. Visit http:// www.dovepress.com/testimonials.php to read real quotes from published authors.

Submit your manuscript here: http://www.dovepress.com/breast-cancer---targets-and-therapy-journal 